\title{
Occurrence and human exposure to brominated and organophosphorus flame retardants via indoor dust in a Brazilian city $^{\text {is }}$
}

\author{
Joyce Cristale $^{a, *}$, Tiago Gomes Aragão Belé ${ }^{a}$, Silvia Lacorte ${ }^{b}$, \\ Mary Rosa Rodrigues de Marchi ${ }^{\text {a }}$ \\ a Department of Analytical Chemistry, Institute of Chemistry, UNESP - Univ Estadual Paulista, Professor Francisco Degni 55, $14800-060$ Araraquara, SP, Brazil \\ ${ }^{\mathrm{b}}$ Department of Environmental Chemistry, IDAEA-CSIC, Jordi Girona 18-26, 08034 Barcelona, Spain
}

\section{A R T I C L E I N F O}

\section{Article history:}

Received 26 May 2017

Received in revised form

26 October 2017

Accepted 28 October 2017

Available online 10 November 2017

\begin{abstract}
A B S T R A C T
Indoor dust is considered an important human exposure route to flame retardants (FRs), which has arised concern due the toxic properties of some of these substances. In this study, ten organophosphorus flame retardants (OPFRs), eight polybrominated diphenyl ethers (PBDEs) and four new brominated flame retardants (NBFRs) were determined in indoor dust from different places in Araraquara-SP (Brazil). The sampled places included houses, apartments, offices, primary schools and cars. The analysis of the sample extracts was performed by gas chromatography coupled to mass spectrometry and two ionization techniques were used (electron ionization - EI; electron capture negative ionization - ECNI). OPFRs were the most abundant compounds and tris(2-butoxyethyl) phosphate (TBOEP), tris(phenyl) phosphate (TPHP), tris(1,3-dichloroisopropyl) phosphate (TDCIPP) and tris(2-chloroisopropyl) phosphate (TCIPP) were present at the highest concentrations. Among the brominated FRs, the most ubiquitous compounds were BDE-209, bis(2-ethylhexyl) tetrabromophthalate (BEH-TEBP) and decabromodiphenyl ethane (DBDPE). Statistical analysis revealed that there were differences among dust typologies for TBOEP, TDCIPP, ethylhexyl diphenyl phosphate (EHDPHP), BDE-209, 2-ethylhexyl 2,3,4,5-tetrabromobenzoate (EH-TBB), BEH-TEBP and DBDPE, which were attributed to different construction materials in each particular environment and to the age of the buildings. The highest levels of brominated FRs were observed in offices, TBOEP was at high concentration in primary schools, and TDCIPP was at high concentration in cars. A preliminary risk assessment revealed that toddlers were exposed to TBOEP levels higher than the reference dose when considering the worst case scenario. The results obtained in this study showed for the first time that although Brazil does not regulate the use of FRs, these substances are present in indoor dust at levels similar to the observed in countries that have strict fire safety standards, and that humans are exposed to complex mixtures of these contaminants via indoor dust.
\end{abstract}

(C) 2017 Elsevier Ltd. All rights reserved.

\section{Introduction}

Indoor dust is considered an important human exposure route to semivolatile organic compounds (e.g. organochlorine pesticides, phthalates, polycyclic aromatic hydrocarbons, flame retardants, etc.) via respiration or ingestion of dust particles (Ait Bamai et al., 2014; Ali et al., 2013; Qi et al., 2014). Concerning Flame Retardants (FRs), the unintentional ingestion of indoor dust

\footnotetext{
* This paper has been recommended for acceptance by Dr. Chen Da.

* Corresponding author.

E-mail address: joycecristale@gmail.com (J. Cristale).
}

represents a human exposure pathway (Jones-Otazo et al., 2005). FRs are applied in a great variety of polymeric materials such as textiles, plastics, rubbers, electronic circuit boards and polyurethane foam, which are used in furniture, materials and coverings for buildings, electric and electronic equipments, etc. (SpecialChem, 2013). Leaching of FRs from materials to dust occurs due mechanical abrasion, direct contact migration and volatilization followed by gas/particle partitioning (Rauert and Harrad, 2015), and consequently, FRs are widely present in indoor dust (e.g. homes, workplaces, schools and transportations) (Ali et al., 2016b; Brommer and Harrad, 2015; Cequier et al., 2014; Saito et al., 2007). 
The concern on human exposure to FRs is because some of these chemicals are endocrine disruptors, neurotoxicants and carcinogenics (Chao et al., 2011; EURAR, 2009; Lyche et al., 2015; WHO, 1998). The polybrominated diphenyl ethers (PBDEs) are toxic to humans and their possible negative effects include reduced reproductive capacity in women, longer periods of menstruation, disturbances in thyroxine (T4), triiodothyronine (T3) and hormones stimulated by the thyroid system, prevalence of diabetes, and delay on neurological development (Chao et al., 2011). These toxic effects associated to their persistency and bioaccumulation potential resulted in bans and a phase out of PBDEs in many countries (OJEU, 2003; UNEP, 2009; USEPA, 2009). Consequently, industries started to use other alternative substances to get specific fire safety standards for their manufactured products and materials. Organophosphorus flame retardants (OPFRs) and new brominated flame retardants (NBFRs) have been used as PBDE substitutes, but some of these chemicals are also suspected to cause negative effects to humans. For example, tris (2-chloroethyl) phosphate (TCEP) and tris (2,3-dichloropropyl) phosphate (TDCIPP) are potential carcinogenic (EURAR, 2009; WHO, 1998).

Human exposure to complex mixtures of PBDEs, NBFRs and OPFRs present in indoor dust was reported for North American (Schreder and La Guardia, 2014), European (Cequier et al., 2014; Cristale et al., 2016; Kademoglou et al., 2017), Asian (Ali et al., 2016b) and Oceanian countries (Ali et al., 2012). The FR levels reported in these studies ranged from units of $\mathrm{ng} \mathrm{g}^{-1}$ to tens of $\mu \mathrm{g} \mathrm{g}^{-1}$ and their distribution was related to the consumption patterns of FR formulations in each country or region. In contrast, little is known about the presence of FRs in indoor dust in countries that do not regulate the use of these substances, as is the case of many South American countries, including Brazil.

The aim of this study was to generate data regarding human exposure to flame retardants via indoor dust in Araraquara (Brazil). PBDEs, NBFRs and OPFRs were determined in indoor dust collected from houses, apartments, primary schools, offices and cars. Measured concentrations were used for estimating the human exposure to FRs via dust ingestion. To the best of our knowledge, this is the first study reporting occurrence and human exposure to FRs via indoor dust in a South American country.

\section{Material and methods}

\subsection{Chemicals}

The analytical standards used in this study included: eight PBDEs (BDE-28, 47, 99, 100, 153, 154, 183 and 209); four NBFRs (bis(2-ethylhexyl) tetrabromophthalate (BEH-TEBP), 2-ethylhexyl 2,3,4,5-tetrabromobenzoate (EH-TBB), 1,2-bis(2,4,6tribromophenoxy)ethane (BTBPE), decabromodiphenyl ethane (DBDPE)); ten OPFRs (tris(2-choroethyl) phosphate (TCEP), tris(2chloroisopropyl) phosphate (TCIPP), tris(1,3-dichloroisopropyl) phosphate (TDCIPP), tris(butyl) phosphate (TNBP), tris(isobutyl) phosphate (TIBP), tris(2-butoxyethyl) phosphate (TBOEP), tris(2ethylhexyl) phosphate (TEHP), tris(phenyl) phosphate (TPHP), 2ethylhexyl diphenyl phosphate (EHDPHP) and tris(methylphenyl) phosphate (TMPP)); four surrogates $\left(3,3^{\prime}, 4,4^{\prime}\right.$-tetrabromodiphenyl ether (BDE-77), decabromo $\left[{ }^{13} \mathrm{C}_{12}\right]$ diphenyl ether (MBDE-209), tri$\mathrm{s}$ (phenyl) phosphate-D15 (TPHP-D15) and tris(butyl) phosphateD27 (TNBP-D27)); and an internal standard (decachlorobiphenyl (PCB-209)). A detailed description of the analytical standards used is presented in the Text S1 (Supplementary Material).

Ethyl acetate (99.9\% purity) was acquired from Sigma-Aldrich (Germany). Toluene was acquired from Macron (USA) and cyclohexane from JT Baker (USA). Florisil cartridges $(1 \mathrm{~g}, 6 \mathrm{~mL})$ were purchased from Agilent (USA).

\subsection{Sampling}

Dust samples were collected from 10 houses (living room and bedroom), 10 apartments (living room and bedroom), 5 primary schools (two classrooms), 5 offices (main room) and 16 cars (cabin) in Araraquara city, Sao Paulo State, Brazil. Dust samples were collected using a household vacuum cleaner Easy Box 1600W (Electrolux). Dust particles were retained in a filter paper $(4-12 \mu \mathrm{m}$ pore size, $150 \mathrm{~mm}$ diameter) folded as a cone and placed between the hose and the crevice tool nozzle. One filter was used in each environment and was replaced with a new one for each site. Each indoor place (houses, apartments, offices and schools) were vacuumed during a total time of $12 \mathrm{~min}$ and included vacuuming the floor, the surfaces and the upholstery (if present). The sampling protocol for houses, apartments and offices consisted in maintaining the vacuuming time ratio of floor, surfaces and upholstery as 3:2:1 ( $\mathrm{min}$ ), respectively. For schools since no upholstery was present the vacuuming time ratio of floor and surfaces was 4:2 (min), respectively. Cars were vacuumed during 6 min, consisting on $3 \mathrm{~min}$ from car seat and $3 \mathrm{~min}$ from other surfaces. Car floor was not vacuumed. Table 1 presents the sampling details. This vacuuming protocol was used for comparison purposes among the different environments.

After sampling, the end of the vacuum cleaner nozzle was wrapped carefully with aluminium foil to avoid loss of sample material and contamination during transportation. In the laboratory, the filter paper cone was removed from the vacuum cleaner and dust samples were sieved $(250 \mu \mathrm{m}$ mesh), placed in glass vials and stored in the freezer until analysis. In this study we analysed the dust size fraction $<250 \mu \mathrm{m}$ because it has higher adherence to human skin (Hee et al., 1985; Yamamoto et al., 2006). Tweezers were used for manual removal of hair and other bulk materials. The nozzle was cleaned with ultrapure water, dried with lint free paper tissue and wrapped in aluminium foil till next sampling.

\subsection{Extraction and analysis}

The extraction protocol described in a previous study (Cristale and Lacorte, 2013) was adapted to fit with the lower sample mass (50 mg of dust) extracted in this study, so that the ratio of extraction solvent/sample mass and the ratio of florisil sorbent mass/solvent volume used for elution were maintained. Details about the extraction and clean-up procedure are presented at Text S2 (Supplementary Material).

PBDEs, NBFRs and OPFRs were determined using a GC Agilent 7890A equipped with 7000A GC-MS Triple Quadrupole which can operate using electron ionization (EI) or chemical ionization (CI). A DB-5MS column of $15 \mathrm{~m}$ (length) x $0.250 \mathrm{~mm}$ (I.D.) x $0.10 \mu \mathrm{m}$ (film) (J\&W Scientific, USA) was used. GC-EI-MS/MS conditions used for determination of FRs were described elsewhere (Cristale and Lacorte, 2013). BDE-209 and DBDPE were determined using electron capture negative ionization (ECNI) mode and selective ion monitoring (SIM) as described elsewhere (Cristale et al., 2012). Table S1 (Suplementary Information) presents the instrumental conditions used in this study.

\subsection{Quality control}

Ten standard solutions at concentrations ranging from 0.001 to $1 \mu \mathrm{g} \mathrm{mL}^{-1}$ in toluene (except for BDE-209 and DBDPE that ranged from 0.01 to $10 \mu \mathrm{g} \mathrm{mL}^{-1}$ ) were used for calibration of the GC-MS system. In order to guarantee a quantification within the linear range $\left(r^{2}>0.99\right.$ and relative error $\left.<20 \%\right)$ more than one calibration curve (with at least 5 points) was used when necessary.

To evaluate the extraction efficiency, a house dust sample was 
Table 1

Sampling protocol for houses, apartments, schools, offices and cars.

\begin{tabular}{|c|c|c|}
\hline & Total sampling time & Vacuuming time details \\
\hline $\begin{array}{l}\text { Houses } \\
(\mathrm{n}=10)\end{array}$ & $12 \mathrm{~min}$ & $\begin{array}{l}\text { living room: } 3 \text { min the floor; } 2 \text { min the surfaces; } 1 \text { min the upholstery (sofa and armchairs) } \\
\text { bedroom: } 3 \text { min the floor; } 2 \text { min the surfaces; } 1 \text { min the upholstery (mattresses) }\end{array}$ \\
\hline $\begin{array}{l}\text { Apartments } \\
(\mathrm{n}=10)\end{array}$ & $12 \mathrm{~min}$ & $\begin{array}{l}\text { living room: } 3 \text { min the floor; } 2 \text { min the surfaces; } 1 \text { min the upholstery (sofa and armchairs) } \\
\text { bedroom: } 3 \text { min the floor; } 2 \text { min the surfaces; } 1 \text { min the upholstery (mattresses) }\end{array}$ \\
\hline $\begin{array}{l}\text { Offices } \\
(\mathrm{n}=5)\end{array}$ & $12 \mathrm{~min}$ & main room: 6 min the floor; 4 min the surfaces; 2 min the upholstery (office chairs) \\
\hline $\begin{array}{l}\text { Schools } \\
(\mathrm{n}=5)\end{array}$ & $12 \mathrm{~min}$ & $\begin{array}{l}2 \text { classrooms where children from } 1 \text { to } 5 \text { years old stay most of time. } \\
\text { For each classroom: } 4 \text { min the floor; } 2 \text { min surfaces (tables, chairs, toy shelves) }\end{array}$ \\
\hline $\begin{array}{l}\text { Cars } \\
(\mathrm{n}=16)\end{array}$ & $6 \mathrm{~min}$ & Cabin: 3 min the car seats; 3 min the surfaces (doors, car dashboard and seat belt) \\
\hline
\end{tabular}

$\mathrm{n}-$ number of places/cars sampled.

spiked with OPFRs, PBDEs and NBFRs at $500 \mathrm{ng} \mathrm{g}^{-1}$, except for BDE209 and DBDPE that were at $5000 \mathrm{ng} \mathrm{g}^{-1}$, and was extracted (in triplicate) and analysed together with the samples. The amount detected in the dust sample used to determine the method efficiency was subtracted for the recovery calculation. The recoveries ranged from 60 to $128 \%$ and the relative standard deviation (RSD) from $0.004 \%$ to $12 \%$ for all target compounds. The reference standard material SRM 2585 (NIST) for organic pollutants in house dust was used. This standard material is certified for PBDEs, and for OPFRs the reference concentrations were the ones obtained in an interlaboratoy study (Brandsma et al., 2013). The relative errors for PBDEs ranged from -13 to $12 \%$ with relative standard deviations (RSD) ranging from 2 to $11 \%$, except for BDE-209 that presented a relative error of $110 \%$ and a RSD of $10 \%$. The reason for the anomalous performance for BDE-209 in the SRM 2585 was not identified, but since spiked samples presented an acceptable recovery of $117 \pm 9 \%$, no recovery correction was performed for BDE-209 in the samples. For OPFRs in the SRM 2585, the relative errors ranged from -25 to $25 \%$, with a RSD ranging from 2 to $9 \%$. A better performance was obtained in this study for TBOEP in the SRM 2585 (relative error $=-25 \%$, RSD $=2$ ) than in our previous study (Cristale and Lacorte, 2013), when this compound presented an error of $-80 \%$ and RSD of $3 \%$ for the same certified reference material. This improvement in TBOEP recovery was attributed to the use of a smaller SPE cartridge ( $1 \mathrm{~g}$ ) and of a different brand than the one used in the previous work $(5 \mathrm{~g})$. Results obtained for the spiked samples and for the SRM 2585 are presented at Table S2. The average recoveries of the surrogates in dust extracts were $103 \pm 10 \%$ for TNBP-D15, $97 \pm 9 \%$ for TPHP-D15, $96 \pm 9 \%$ for BDE-77 and $93 \pm 20 \%$ for MBDE-209.

Given that FRs are present in a variety of materials present in laboratories, blank contamination is expected as previously reported (Brandsma et al., 2013). In order to evaluate the influence of blank contamination, procedural blanks (with no matrix) were extracted with each sample batch $(n=6)$. OPFRs and BDE-209 were detected in the procedural blanks, and the average blank concentrations are presented at Table S3. For those compounds, method detection limits (MDL) were calculated as the average values of the blank contribution $(n=6)$ plus three times the standard deviation. MDL for OPFRs ranged from 5.9 to $175 \mathrm{ng} \mathrm{g}^{-1}$, and MDL for BDE-209 was $33 \mathrm{ng} \mathrm{g}^{-1}$. For the other flame retardants (not present in the blanks) the MDL was calculated as three times the signal to noise ratio, and ranged from 0.4 to $29 \mathrm{ng} \mathrm{g}^{-1}$. MDL for each target compound is presented in Table S2. Given that concentrations of target compounds observed in the blanks were in general much lower than the concentration observed in the samples, no blank correction was performed for the samples.

\subsection{Statistical analysis}

ANOVA and student $t$-test were performed using the excel software. The non detected concentrations were assigned as half of the MDL for the statistical evaluation. Data was log-normalized in order to fit a normal distribution. Data sets (houses, apartments, offices, schools and cars) were therefore compared using ANOVA and the statistical significance was obtained when $F>F$ critical. Concentration of FRs in houses and apartments were compared using the student $t$-test, and the statistical significance was obtained when $T$-statistic $>T$-critical.

\subsection{Human exposure}

For the estimation of the daily intake of FRs via indoor dust ingestion, the median and 95th percentile concentrations of each FR in dust from residences (combining house and apartment data), office dust, school dust and car dust were considered representing two different scenarios, the mean and the high exposure, respectively. For adults, it was calculated as Ali et al. (2013) with some modifications:

$T D I_{A}=\frac{\left[\left(C_{H} F_{H}\right)+\left(C_{O} F_{O}\right)+\left(C_{C} F_{C}\right)\right] D I_{A}}{B W_{A}}$

were $T D I_{A}$ is the total daily intake rate of the FR by adults ( $\mathrm{ng} \mathrm{kg}^{-1}$ day $\left.^{-1}\right) . C_{H}, C_{O}$ and $C_{C}$ are the concentration $\left(\mathrm{ng} \mathrm{g}^{-1}\right)$ of the FR in dust from homes, offices and cars, respectively. $F_{H}, F_{O}$ and $F_{C}$ are the fraction of the time that adults spend at homes, offices and in cars, respectively. $D I_{A}$ is the dust ingestion rate for adults $\left(\mathrm{g} \mathrm{day}^{-1}\right)$ and $\mathrm{BW}_{\mathrm{A}}$ is the body weight for adults $(\mathrm{kg})$.

Similarly, the total daily intake for toddlers $\left(\mathrm{TDI}_{\mathrm{T}}\right)$ was calculated as:

$T D I_{T}=\frac{\left[\left(C_{H} F_{H}\right)+\left(C_{S} F_{S}\right)+\left(C_{C} F_{C}\right)\right] D I_{T}}{B W_{T}}$

where $C_{S}$ is the concentration ( $\mathrm{ng} \mathrm{g}^{-1}$ ) of the FR in dust from schools, $F_{S}$ is the fraction of the time that toddlers spend at schools, $D I_{T}$ is the daily dust ingestion rate for toddlers $\left(\mathrm{g} \mathrm{day}^{-1}\right)$ and $B W_{T}$ is the body weight for toddlers $(\mathrm{kg})$.

For both, adults and toddlers, it was assumed that they spend $63 \%$ of time $(\sim 15 \mathrm{~h})$ at home $\left(F_{H}=0.63\right)$ and $4 \%$ of time $(\sim 1 \mathrm{~h})$ in the $\operatorname{car}\left(F_{C}=0.041\right) . F_{O}$ for adults and $F_{S}$ for toddlers were both assumed as $33 \%$ of time $\left(\sim 8 \mathrm{~h}, F_{S}=F_{O}=0.33\right)$. The values used for $D I, B W$ were 
the ones frequently used in literature for assessment of FR ingestion via indoor dust for adults and toddlers (Ali et al., 2016b; JonesOtazo et al., 2005). Two dust ingestion rates were used in this study for adults $\left(D I_{A}: 0.020\right.$ and $\left.0.050 \mathrm{~g} \mathrm{day}^{-1}\right)$ and toddlers $\left(D I_{T}\right.$ : 0.050 and $0.200 \mathrm{~g} \mathrm{day}^{-1}$ ), representing the mean exposure and the high exposure scenarios (Jones-Otazo et al., 2005). The higher DI levels for toddlers than for adults is due to their close-to-ground behaviour and their frequent hand-to-mouth contact, resulting in a higher dust intake. Finally, $B W_{A}$ and $B W_{T}$ were 70 and $12 \mathrm{~kg}$, respectively.

\section{Results and discussion}

The three flame retardant families (OPFRs NBFRs and PBDEs) determined in indoor dust samples evidenced the different levels and profiles according to each environment. It is relevant that all families of FRs were detected in all dust samples, which is in agreement with other studies that indicate an ubiquitous presence of complex mixtures of FRs in indoor dust (Cequier et al., 2014; Cristale et al., 2016). The compounds and the levels detected permitted to estimate the potential risks to humans exposed to these compounds by unintentional ingestion of dust particles. In the following subsections the results are presented and compared, and the last subsection presents a risk assessment to humans.

\subsection{FR levels and profile}

All dust samples collected in houses, apartments, primary schools, offices and cars contained OPFRs, PBDEs and NBFRs, although their distribution profile varied among dust typologies (Fig. 1). Table 2 presents the median, maximum, minimum and detection frequency observed for each target compound in each set of samples. In all the places, OPFRs were the compounds present at the highest concentrations. Concerning PBDEs, BDE-47, BDE-99 and BDE-209 were the most frequently detected compounds being the latter the most abundant PBDE. NBFRs were detected in all the samples, and DBDPE was the most frequent and abundant compound.

Houses and apartments: TBOEP ranged from 1550 to $348000 \mathrm{ng} \mathrm{g}^{-1}$ and was the most abundant OPFR followed by TDCIPP (up to $61200 \mathrm{ng} \mathrm{g}^{-1}$ ), TPHP (up to $10700 \mathrm{ng} \mathrm{g}^{-1}$ ) and TCIPP (up to $6420 \mathrm{ng} \mathrm{g}^{-1}$ ) (Fig. $1 \mathrm{a}$ and d). Concerning brominated FRs, in most of samples BDE-209 and DBDPE were responsible for more than $80 \%$ of the total PBDE and NBFR content, respectively. Sample $\mathrm{H} 1$ presented a different PBDE profile and high contribution of BDE47 and BDE-99, which was attributed to the presence of many old electronics and old upholstered furniture and mattresses in this house. The variations observed for the FR relative distribution in houses and apartments (Fig. $1 \mathrm{a}-\mathrm{f}$ ) were expected since the occurrence of FRs depends on the type materials (polymers, textiles, wood, etc.) and the products (EEE, upholstered furniture, mattresses, etc.) present in each environment (Cristale et al., 2016).

Schools: TBOEP ranged from 3660 to $4590000 \mathrm{ng} \mathrm{g}^{-1}$ and was responsible for almost all OPFR content in dust from schools (Fig. 1g), except for S2, that presented a high contribution of TPHP and TDCIPP and a lower content of TBOEP. Only one of the sampled rooms in school S2 had PVC floor coverings, which is a TBOEP source (Ali et al., 2012), but appeared to be very clean and with little dust, while the other rooms had ceramic covering and more dust on the floor, which would explain the different profile encountered. As also observed in residences (houses and apartments), BDE-209 and DBDPE were the most abundant brominated compounds in schools (Fig. $1 \mathrm{~h}$ and $\mathrm{i}$ ), with concentrations ranging from 93.9 to $1210 \mathrm{ng} \mathrm{g}^{-1}$ and from 213 to $703 \mathrm{ng} \mathrm{g}^{-1}$, and the other brominated FRs were rarely detected.
Offices: The FR profile in offices (Fig. $1 \mathrm{j}-\mathrm{l}$ ) was similar to residences, except for the NBFRs due the higher BEH-TEBP levels in offices, ranging from 342 to $7550 \mathrm{ng} \mathrm{g}^{-1}$. Two out of the five office samples presented BEH-TEBP at levels that corresponded to more than $60 \%$ of the total NBFR content. BEH-TEBP is used in polyurethane foam and in PVC (Ali et al., 2012), and so the possible sources of this compound in offices include upholstered office chairs and flexible PVC wire cables. The sample $\mathrm{O} 2$ presented different profile of OPFRs and NBFRs, with lower contribution of TBOEP and higher contribution of EH-TBB. This office was located in a mall that probably influenced the FR profile in this dust sample.

Cars: OPFRs were the most abundant FRs, with $\sum$ OPFRs ranging from $108000 \mathrm{ng} \mathrm{g}^{-1}$ to $2050000 \mathrm{ng} \mathrm{g}^{-1}$. TDCIPP (ranging from 1050 to $1600000 \mathrm{ng} \mathrm{g}^{-1}$ ) was the most abundant compound, followed by TPHP (ranging from 1030 to $464000 \mathrm{ng} \mathrm{g}^{-1}$ ) and TBOEP (ranging from 2050 to $153000 \mathrm{ng} \mathrm{g}^{-1}$ ). Fig. $1 \mathrm{n}$ and o show that the relative distribution of PBDEs and NBFRs in cars followed the same trend observed for the other sampled places, with BDE-209 and DBDPE as the most abundant PBDE and NBFR, respectively, except for the sample C16 that presented an atypical behaviour with BEH-TEBP and EH-TBB at very high concentrations (BEH-TEBP at $592000 \mathrm{ng} \mathrm{g}^{-1}$, EH-TBB at $952000 \mathrm{ng} \mathrm{g}^{-1}$ ).

The higher concentration of OPFRs than PBDEs and NBFRs in dust is a trend also observed in many other countries, such as Norway (Cequier et al., 2014), Saudi Arabia (Ali et al., 2016b), Spain (Cristale et al., 2016), Japan (Mizouchi et al., 2015) and USA (Schreder and La Guardia, 2014). Also in accordance to our data, these previous studies indicated BDE-209 as the most abundant PBDE, and DBDPE and BEH-TEBP as the most abundant NBFRs. The OPFR distribution in dust from residences reported in literature vary and it is related to the use of OPFRs in each particular country or region, but in general the most abundant OPFRs are the same found in this study. In Japanese houses, TBOEP, TCIPP and TPHP were detected in all samples while TNBP, TCEP, TDCIPP and TEHP had a detection frequency lower than $50 \%$, and TBOEP was present at concentrations about 40 times higher than those observed for TPHP and TCIPP (Tajima et al., 2014). In Norway, TBOEP was the most abundant compound in living rooms (median $87200 \mathrm{ng} \mathrm{g}^{-1}$ ) and classrooms (median $13400 \mathrm{ng} \mathrm{g}^{-1}$ ), followed by TCIPP (2800 and $2040 \mathrm{ng} \mathrm{g}^{-1}$ in houses and classrooms, respectively) (Cequier et al., 2014). On the other hand, TPHP was reported at the highest average concentration and was the only OPFR detected in all the samples in houses from Egypt, while TBOEP was the second most abundant compound with a detection frequency of $25 \%$ for homes and 35\% for offices (Abdallah and Covaci, 2014). Concerning car dust, OPFRs were reported at higher levels than PBDEs and NBFRs in Saudi Arabia (Ali et al., 2016b), Kuwait and Pakistan (Ali et al., 2013), and both studies also reported the chlorinated phosphate esters as the most abundant OPFRs, BDE-209 as the most abundant PBDE, and DBDPE and BEH-TEBP as the most abundant NBFRs.

A direct comparison among FR levels in dust of different studies is only possible for studies that use the same sampling methodology (e.g. vacuum cleaner bag dust - VCBD, vaccum cleaner dust collected by the researchers - VCDCR, etc.) and the same dust fraction size for analysis, given that both parameters affect the observed FR concentration in dust extracts (Allen et al., 2008; Cao et al., 2014; Cristale et al., 2016). Mizouchi et al. (2015) reported the FR levels in dust samples collected using VCDCR and in the size fraction $<250 \mu \mathrm{m}$, allowing a comparison to the levels observed in this study. The median observed concentration in Japanese houses for TCIPP (1700 $\left.\mathrm{ng} \mathrm{g}^{-1}\right)$ and TDCIPP $\left(2200 \mathrm{ng} \mathrm{g}^{-1}\right)$ were at the same order of magnitude than in our studied residences (Table 1), while TCEP (median $2700 \mathrm{ng} \mathrm{g}^{-1}$ ) was at higher concentrations in Japanese houses. These chloroalkyl phosphates were more frequently detected in the Japanese schools ( $80-100 \%$ of samples) than in our 


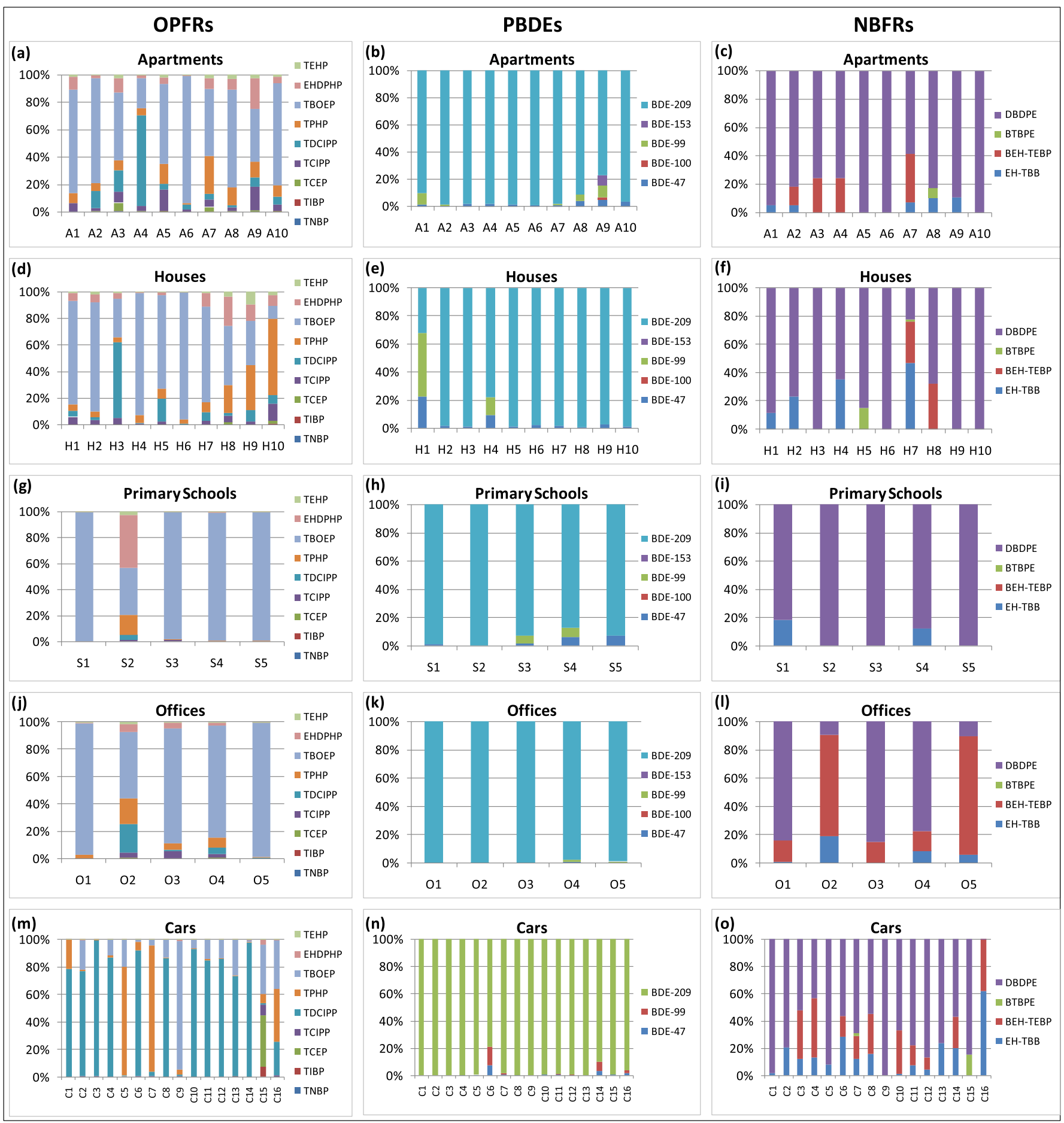

Fig. 1. Distribution of OPFRs, PBDEs and NBFRs in apartments $(a-c)$, houses $(d-f)$, schools $(g-i)$, offices $(j-l)$ and cars $(m-0)$.

studied schools. On the other hand, TNBP, TIBP and TEHP were more frequently detected in this study, and although we observed high TBOEP concentrations in schools (median $551000 \mathrm{ng} \mathrm{g}^{-1}$ ), the Japanese houses had higher TBOEP concentrations (median $82000 \mathrm{ng} \mathrm{g}^{-1}$ ). Concerning aryl phosphates, median concentration of TPHP in schools $\left(2200 \mathrm{ng} \mathrm{g}^{-1}\right)$ were similar to this study, but were at lower concentration in Japanese houses (median $820 \mathrm{ng} \mathrm{g}^{-1}$ ). In contrast, the median TMPP concentration was $1200 \mathrm{ng} \mathrm{g}^{-1}$ in houses and $6800 \mathrm{ng} \mathrm{g}^{-1}$ in schools from Japan, but it was not detected in our dust samples. Concerning PBDEs, the $\sum$ PBDEs was higher in Japanese houses (median $1300 \mathrm{ng} \mathrm{g}^{-1}$ ) than in this study (median $450 \mathrm{ng} \mathrm{g}^{-1}$ ), but were at similar levels in schools. Finally, DBDPE was at lower concentration in Japanese houses (median $220 \mathrm{ng} \mathrm{g}^{-1}$ ) and schools (median $50 \mathrm{ng} \mathrm{g}^{-1}$ ) than in our samples. This comparison demonstrate that although Brazil does not have fire safety standards for materials manufactured in the country, FRs are present in the materials and goods found inside homes and schools, and that the concentrations of these FRs in 
Table 2

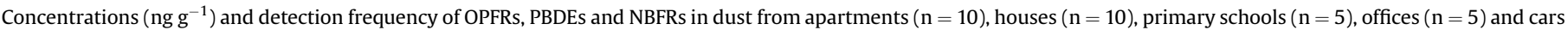
$(\mathrm{n}=16)$.

\begin{tabular}{|c|c|c|c|c|c|c|c|c|c|c|}
\hline & \multicolumn{2}{|c|}{ Apartments } & \multicolumn{2}{|c|}{ Houses } & \multicolumn{2}{|c|}{ Primary Schools } & \multicolumn{2}{|c|}{ Offices } & \multicolumn{2}{|l|}{ Cars } \\
\hline & Freq. & Median (Min. - Max) & Freq. & Median (Min. - Max) & Freq. & Median (Min. - Max) & Freq. & Median (Min. - Max) & Freq. & Median (Min. - Max.) \\
\hline TCEP & $90 \%$ & $237(136-826)$ & $60 \%$ & $230(153-421)$ & $40 \%$ & $4740(547-8930)$ & $80 \%$ & $237(145-681)$ & $69 \%$ & $4200(138-40400)$ \\
\hline TCIPP & $100 \%$ & $1870(820-6420)$ & $100 \%$ & $771(442-2280)$ & $100 \%$ & $385(109-69200)$ & $100 \%$ & $1820(763-2510)$ & $100 \%$ & $2420(315-9220)$ \\
\hline TDCIPP & $90 \%$ & $2250(600-61200)$ & $100 \%$ & $1370(369-28600)$ & $20 \%$ & 397 & $80 \%$ & $4480(249-10500)$ & $100 \%$ & $506000(1050-1600000)$ \\
\hline TNBP & $90 \%$ & $28.1(20.0-48.1)$ & $100 \%$ & $12.3(7.95-57.2)$ & $100 \%$ & $17.1(7.66-40.7)$ & $100 \%$ & $40.8(8.76-64.0)$ & $94 \%$ & $24.4(14.1-47.6)$ \\
\hline TIBP & $90 \%$ & $40.1(15.0-189)$ & $100 \%$ & $30.7(16.3-79.3)$ & $60 \%$ & $109(15.6-551)$ & $100 \%$ & $51.7(22.9-119)$ & $100 \%$ & $526(14.4-7640)$ \\
\hline TBOEP & $100 \%$ & $22100(6860-123000)$ & $100 \%$ & $15900(1550-348000)$ & $100 \%$ & $551000(3660-4590000)$ & $100 \%$ & $\begin{array}{l}72800(23900 \\
-1910000)\end{array}$ & $100 \%$ & $62200(2050-153000)$ \\
\hline TEHP & $100 \%$ & $549(259-2000)$ & $100 \%$ & $397(143-2020)$ & $100 \%$ & $537(224-4320)$ & $100 \%$ & $500(248-6490)$ & $100 \%$ & $576(142-2040)$ \\
\hline ТPHP & $100 \%$ & $3830(989-8460)$ & $100 \%$ & $3900(542-10700)$ & $100 \%$ & $2210(1520-6680)$ & $100 \%$ & $6420(1740-47000)$ & $100 \%$ & $86200(1030-464000)$ \\
\hline EHDPHP & $100 \%$ & $1750(1060-4870)$ & $100 \%$ & $1590(648-5120)$ & $100 \%$ & $5150(2520-9700)$ & $100 \%$ & $2140(1380-10500)$ & $100 \%$ & $1750(536-3970)$ \\
\hline$\sum$ OPFRs & & $\begin{array}{l}42600(14400 \\
-134000)\end{array}$ & & $\begin{array}{l}26400(11100 \\
-363000)\end{array}$ & & $\begin{array}{l}560000(10100 \\
-4690000)\end{array}$ & & $\begin{array}{l}88000(34500 \\
-1980000)\end{array}$ & & $\begin{array}{l}541000(108000 \\
-2050000)\end{array}$ \\
\hline BDE-47 & $100 \%$ & $9.01(5.06-27.8)$ & $100 \%$ & $8.04(4.50-140)$ & $80 \%$ & $8.21(3.15-29.7)$ & $80 \%$ & $12.8(7.54-34.4)$ & $69 \%$ & $31.3(4.25-188)$ \\
\hline BDE-100 & $10 \%$ & 6.93 & $0 \%$ & & $0 \%$ & & $0 \%$ & & & \\
\hline BDE-99 & $50 \%$ & $23.5(13.6-31.4)$ & $20 \%$ & $153(20.3-286)$ & $40 \%$ & $33.1(30.4-35.9)$ & $60 \%$ & $30.2(12.3-53.0)$ & $38 \%$ & $100(8.45-352)$ \\
\hline BDE-153 & $10 \%$ & 27.1 & $0 \%$ & & $0 \%$ & & $0 \%$ & & & \\
\hline BDE-209 & $100 \%$ & $425(254-1420)$ & $100 \%$ & $407(125-1200)$ & $100 \%$ & $419(93.9-1210)$ & $100 \%$ & $4240(1760-25200)$ & $100 \%$ & $1570(291-3950)$ \\
\hline$\sum$ PBDEs & & $437(270-1450)$ & & $481(160-1210)$ & & $480(101-1210)$ & & $4330(1760-25000)$ & & $1140(291-3980)$ \\
\hline EH-TBB & $50 \%$ & $96.1(35.1-110)$ & $40 \%$ & $134(29.9-725)$ & $40 \%$ & $60.4(47.5-73.2)$ & $80 \%$ & $413(28.0-1580)$ & $89 \%$ & $68200(16.4-952000)$ \\
\hline $\begin{array}{l}\text { BEH- } \\
\text { TEBP }\end{array}$ & $40 \%$ & $338(176-462)$ & $20 \%$ & $405(357-454)$ & $0 \%$ & & $100 \%$ & $908(342-7550)$ & $63 \%$ & $59700(325-592000)$ \\
\hline ВТВРЕ & $10 \%$ & 74.3 & $20 \%$ & $55.0(30.1-79.9)$ & $0 \%$ & & $0 \%$ & & $13 \%$ & $96.5(72.4-121)$ \\
\hline DBDPE & $100 \%$ & $980(301-2140)$ & $100 \%$ & $397(148-743)$ & $100 \%$ & $296(213-703)$ & $100 \%$ & $2010(839-5000)$ & $100 \%$ & $1360(422-3820)$ \\
\hline$\sum$ NBFRs & & $1090(336-2280)$ & & $557(148-1550)$ & & $296(225-703)$ & & $5940(2350-8980)$ & & $1960(554-1550000)$ \\
\hline
\end{tabular}

indoor dust are similar or even higher than in Japan that have a more strict fire safety standards. In addition, many electronics, textiles, coatings and construction materials are imported or contain imported components from countries that have fire safety standards, such as Asian, European and North America countries. These imported materials probably pose a significant influence on the FR levels observed in indoor dust from Araraquara.

Concerning car dust, the median levels of OPFRs, PBDEs and NBFRs observed in this study were from 3.1 (BDE-47) to 5700 (EHTBB) times higher than the levels observed in VCDCR (size fraction $<250 \mu \mathrm{m}$ ) from Jeddah (Kingdom of Saudi Arabia) (Ali et al., 2016a), except for TNBP that presented twice higher levels in Jeddah car dust samples than in this study. Thirteen out of the sixteen cars sampled in this study were manufactured in Brazil and so the high FR levels observed in car dust indicates a high usage of these substances by the Brazilian automotive industry.

\subsection{Comparison among dust typologies}

Analysis of variance (ANOVA) was performed for comparison among levels of each FR in each sample set, and the results are presented at Table S4 and S5 (Supplementary Material). ANOVA was performed among the indoor places (houses, apartments, offices and schools) and also among all the sample sets (indoor places and cars). The ANOVA for the indoor places indicated that there were statistical differences among groups for TBOEP, EHDPHP, BDE209, EH-TBB, BEH-TEBP and DBDPE. Besides these compounds, the ANOVA also indicated difference for TDCIPP when the car data was included. The specific profiles in each environment can be attributed to the specific materials containing FRs, according to the fire safety protocols. The high levels of TBOEP in schools compared to the other sampled places seems to be associated to the presence of PVC floor coverings in most of sampled classrooms, given that TBOEP is used as additive in this type of material (Ali et al., 2012). TBOEP is also present as a component in floor polishes (Tajima et al.,
2014). On the other hand, the general high levels of brominated FRs in offices are attributed to the presence of high amounts of EEEs (several computers, printers, photocopy machine, etc.). Finally, a much higher abundance of TDCIPP was observed for car dust than for indoor dust. TDCIPP is an additive of polyurethane foam mainly used in the automotive industry. TDCIPP operates in the same marketplace as TCIPP, but due to its higher price, TDCIPP is preferably used in those applications where a more efficient flame retardancy is required to meet specific fire safety standards (EURAR, 2008b).

Fig. 2 presents the box-plot distribution of target flame retardants in each of the studied places (apartments, houses, primary schools, offices and cars). OPFRs were divided in three groups, based on their chemical structure: chloroalkyl phosphates ( $\sum$ ChlAlkP) consisting on TCEP, TCIPP and TDCIPP; alkyl phosphates ( $\sum$ AlkP) consisting on TIBP, TNBP, TBOEP and TEHP; and aryl phosphates ( $\sum$ AryP) consisting on TPHP and EHDPP. As depicted at Fig. 2, offices presented the highest levels of all FR groups (organophosphorus and brominated compounds), except for alkyl phosphates (Fig. 2b) that were more abundant in schools due to the high TBOEP levels, and for chloroalkyl phosphates in cars due the high levels of TDCIPP. Aryl phosphates were present at similar levels in all the places, although a higher variability was observed in cars (Fig. 2c). Schools presented the lowest levels of chloroalkyl phosphates, which is in accordance with the fact that inside most of sampled rooms there were no/few mattresses and upholstered furniture, which usually contain these FRs (EURAR, 2008a; SCHER, 2012).

The main source of FRs in dust from residences are the polymers used in coverings, furniture, foams, electronics, etc. (Ali et al., 2012). Many FRs are semivolatile compounds and can leach from the polymeric materials containing FRs (Saito et al., 2007). Consequently, FR levels in indoor particles are generally much higher than in outdoor particles (Besis and Samara, 2012; Cao et al., 2014; Khan et al., 2016). Considering that larger outdoor particles are 

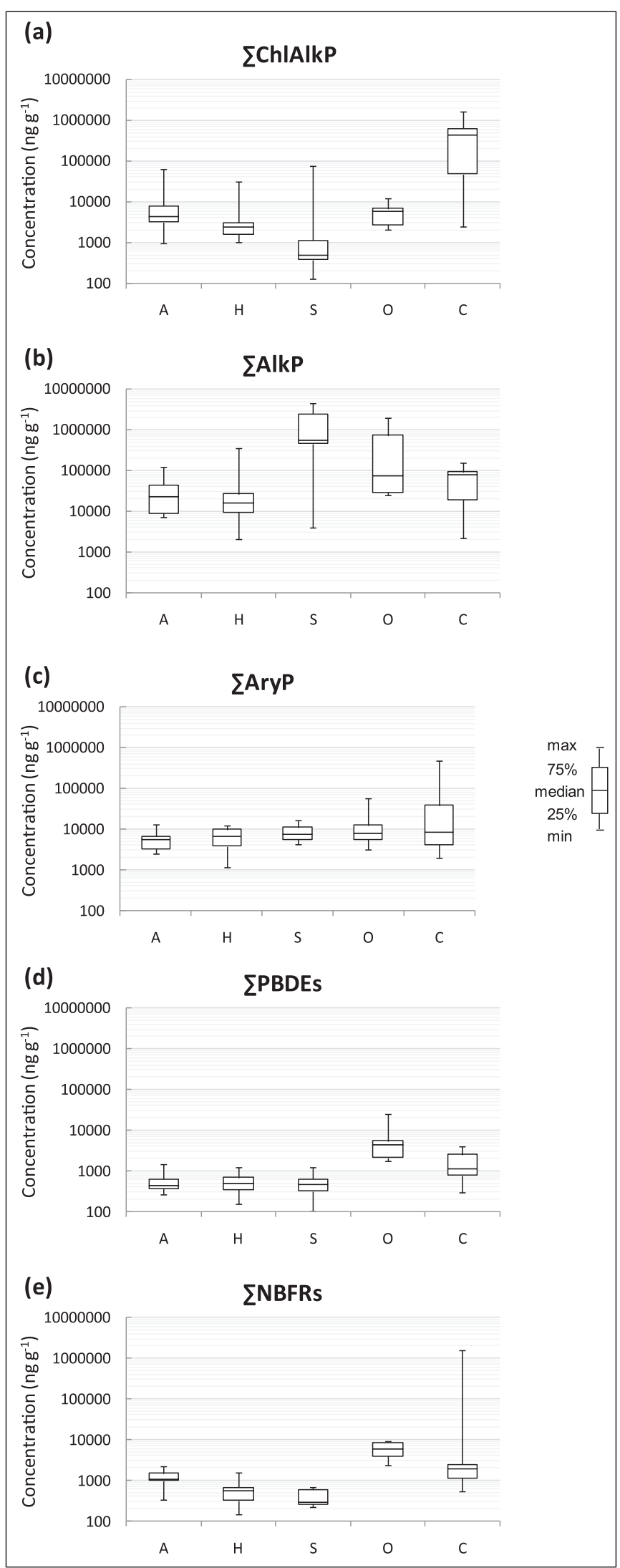

Fig. 2. Levels ( $\mathrm{ng} \mathrm{g}^{-1} \mathrm{dw}$ ) of OPFRs, PBDEs and NBFRs observed in dust from apartments (A), houses (H), schools (S), offices (O) and cars (C). affected by gravity tending to decrease its concentration with height (Chan and Kwok, 2000), and assuming that this behaviour affects the abundance of indoor dust, a comparison among FR concentrations in dust from houses (first floor) and apartments (located at 3th floor or higher) was performed in order to test the hypothesis that particles from outdoors could dilute the FR levels in indoor dust. This hypothesis was not confirmed since the tendency of increasing concentration in apartments compared to houses was not systematically observed, which would be the expected result if a dilution effect was occurring. Both sample set (houses and apartments) presented fluctuation on FR levels, but in general they were at the same order of magnitude as shown at Fig. 2. Median $\sum$ PBDEs concentrations were similar for apartments $\left(437 \mathrm{ng} \mathrm{g}^{-1}\right)$ and houses $\left(481 \mathrm{ng} \mathrm{g}^{-1}\right.$ ). On the other hand, NBFRs tend to be at higher concentrations in apartments (median $1090 \mathrm{ng} \mathrm{g}^{-1}$ ) than in houses (median $557 \mathrm{ng} \mathrm{g}^{-1}$ ). This behaviour is probably related to the age of the buildings, given that most of the apartments are less than 10 years old and most of the sampled houses are older than 20 years. New constructions have often newer furniture, which may contain NBFRs. This same trend was also observed for chloroalkyl phosphates, which are also used as PBDEs substitutes in polyurethane foam (Dodson et al., 2012). These results were confirmed by using the statistical student $t$-test considering all the target compounds in houses and apartments (Table S6, Supplementary Material) and no differences ( $T$-statistic $<T$-critical) were observed, except for DBDPE and TCIPP.

Concerning the FR levels in homes, schools and workplaces, the trends observed in this study are in line with similar studies from other countries. A higher abundance of FRs in dust from residences than in classrooms was also observed in Spain (Cristale et al., 2016), Japan (Mizouchi et al., 2015) and Norway (Cequier et al., 2014). In accordance to our data, these previous studies have reported higher TBOEP levels in schools than in homes, attributed to PVC-based flooring and to the use of floor polishers/waxes containing TBOEP. Higher levels of brominated FRs in offices than in homes was also observed in Egypt (Hassan and Shoeib, 2015). Finally, a higher FR levels in car dust than in house dust is also in accordance to the literature (Ali et al., 2013, 2016b; Hassan and Shoeib, 2015).

\subsection{Human exposure}

Once dust is ingested, part of the FRs adsorbed in dust particles can be released and then be susceptible to undergo transportation across the intestinal epithelium and finally reach the systemic circulation. In this study, a risk assessment was performed considering an absorption rate of $100 \%$, representing the worst scenario (Jones-Otazo et al., 2005).

Table 3 presents the typical high and mean exposure of adults and toddlers to each FR via dust ingestion and the respective reference dose (Ali et al., 2013) for each compound. Considering the mean dust ingestion, the human exposure (adults and toddlers) ranged from 0.008 to $6100 \mathrm{ng} \mathrm{kg}^{-1} \mathrm{day}^{-1}$ for OPFRs, from 0.0012 to $5.2 \mathrm{ng} \mathrm{kg}^{-1} \mathrm{day}^{-1}$ for PBDEs and from 0.014 to $57 \mathrm{ng} \mathrm{kg}^{-1} \mathrm{day}^{-1}$ for NBFRs. For the high dust ingestion scenario, an exposure ranging from 0.020 to 24000 for $n g \mathrm{~kg}^{-1} \mathrm{day}^{-1}$ for OPFRs, from 0,0031 to $21 \mathrm{ng} \mathrm{kg}^{-1} \mathrm{day}^{-1}$ for PBDEs and from 0.036 to $230 \mathrm{ng} \mathrm{kg}^{-1} \mathrm{day}^{-1}$ for NBFRs was assessed for adults and toddlers, respectively. Note that even overestimating the daily intake of FRs (based on $100 \%$ of adsorption rate) the exposure to most of FRs via dust ingestion was several magnitude orders lower than the reference dose considering both adults and toddlers, what is in accordance with the literature (Ali et al., 2012, 2016b; Kim et al., 2013). The exception was for toddler exposure to TBOEP, that was higher (24000 $\mathrm{ng} \mathrm{kg}^{-1}$ day $^{-1}$ ) than the reference dose ( $\left.15000 \mathrm{ng} \mathrm{kg}^{-1} \mathrm{day}^{-1}\right)$ in the worst scenario (high dust ingestion, 95\% percentile levels). The high 
Table 3

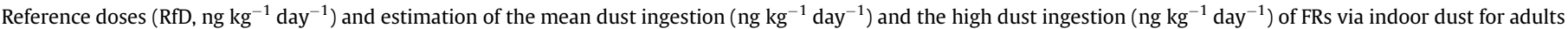
and toddlers.

\begin{tabular}{|c|c|c|c|c|c|c|c|c|c|}
\hline & \multirow[t]{3}{*}{ RfD Values $^{\mathrm{a}}$} & \multicolumn{4}{|c|}{ Mean dust Ingestion } & \multicolumn{4}{|c|}{ High dust Ingestion } \\
\hline & & \multicolumn{2}{|l|}{ Toddles } & \multicolumn{2}{|l|}{ Adult } & \multicolumn{2}{|l|}{ Toddles } & \multicolumn{2}{|l|}{ Adult } \\
\hline & & median & $95 \%$ percentile & median & $95 \%$ percentile & median & $95 \%$ percentile & median & $95 \%$ percentile \\
\hline TCEP & 22000 & 7.2 & 17 & 0.070 & 0.41 & 29 & 67 & 0.18 & 1.0 \\
\hline TCIPP & 80000 & 3.8 & 87 & 0.40 & 0.94 & 15 & 350 & 1.0 & 2.3 \\
\hline TDCIPP & 15000 & 78 & 330 & 5.7 & 24 & 310 & 1300 & 14 & 59 \\
\hline TNBP & 24000 & 0.084 & 0.19 & 0.0080 & 0.015 & 0.34 & 0.75 & 0.020 & 0.038 \\
\hline TIBP & & 0.24 & 1.4 & 0.011 & 0.058 & 0.97 & 5.5 & 0.028 & 0.14 \\
\hline TВOEP & 15000 & 820 & 6100 & 11 & 180 & 3300 & 24000 & 28 & 460 \\
\hline TEHP & & 2.0 & 11 & 0.13 & 0.87 & 7.9 & 42 & 0.33 & 2.2 \\
\hline ТРHP & 70000 & 14 & 110 & 1.4 & 10 & 56 & 420 & 3.4 & 26 \\
\hline EHDPHP & & 12 & 26 & 0.53 & 1.8 & 48 & 110 & 1.3 & 4.4 \\
\hline$\sum$ OPFRs & & 950 & 6500 & 21 & 210 & 3800 & 26000 & 52 & 520 \\
\hline BDE-47 & 100 & 0.035 & 0.15 & 0.0028 & 0.011 & 0.14 & 0.59 & 0.0071 & 0.027 \\
\hline BDE-100 & & 0.018 & 0.018 & 0.0012 & 0.0012 & 0.073 & 0.073 & 0.0031 & 0.0031 \\
\hline BDE-99 & 100 & 0.11 & 0.65 & 0.0073 & 0.046 & 0.44 & 2.6 & 0.018 & 0.12 \\
\hline BDE-153 & 200 & 0.071 & 0.071 & 0.0049 & 0.0049 & 0.28 & 0.28 & 0.012 & 0.012 \\
\hline BDE-209 & 7000 & 1.9 & 5.2 & 0.49 & 2.3 & 7.4 & 21 & 1.2 & 5.6 \\
\hline$\sum$ PBDES & & 2.0 & 5.3 & 0.50 & 2.3 & 8.1 & 21 & 1.25 & 5.7 \\
\hline EH-TBB & 20000 & 0.41 & 57 & 0.061 & 4.0 & 1.6 & 230 & 0.15 & 10 \\
\hline BEH-ТEBP & 20000 & 1.0 & 56 & 0.16 & 4.5 & 4.2 & 220 & 0.39 & 11 \\
\hline ВТВРE & 243000 & 0.21 & 0.23 & 0.014 & 0.016 & 0.84 & 0.91 & 0.036 & 0.039 \\
\hline DBDPE & 333333 & 2.2 & 6.3 & 0.31 & 0.80 & 8.9 & 25 & 0.78 & 2.0 \\
\hline$\sum$ NBFRs & & 3.0 & 72 & 0.74 & 5.7 & 12 & 290 & 1.8 & 14 \\
\hline
\end{tabular}

a Ali et al., 2013.

exposure of toddlers to TBOEP is due the high levels of this compound found in dust from schools, responsible for about $96 \%$ of TBOEP daily intake of toddlers. To the best of our knowledge no study concerning the bioaccessibility of TBOEP is available. TBOEP is a endocrine disruptor (Kojima et al., 2013) and the high levels found in indoor dust from Araraquara-SP could pose a risk to the exposed population, especially toddlers.

Although the TDI for adults and toddlers were lower than the reference dose for most of OPFRs, except for TBOEP, it is important to consider that reference doses were calculated on basis of noobserved-adverse-effects-levels (NOAELs) (Ali et al., 2012) and that the levels detected are high and may have unexpected repercussions on human health. Overall, the toxicity of most of FRs is not completely understood, and the effects of exposure to complex mixtures of FRs can result in dose-additive effects causing adverse effects even when the individual concentration of compounds are low (Kojima et al., 2013).

\section{Conclusions}

OPFRs, PBDEs and NBFRs were detected in all dust samples collected from houses, apartments, schools, offices and cars from Araraquara-SP. Higher FR levels in offices than in houses and schools was observed, except for TBOEP that was at higher levels in schools. In addition, the levels of TDCIPP in cars were higher than in the other sampled sites. In general, the profile of FRs was similar to the observed in other countries, being OPFRs the most prevalent FRs. Newer houses/apartments presented higher levels of OPFRs and NBFRs than the older ones. These results are in agreement with the phase-out and bans of PBDEs around the world, resulting in an increase on the use of alternative FRs. The preliminary risk assessment revealed that the levels of FRs in dust are below the reference doses proposed by Ali et al. (2013) and that the risk of hazardous effects is low. However, a risk to toddlers associated to TBOEP exposure was observed. The results of this study revealed for the first time that population from a medium-sized city in Brazil are exposed to complex mixture of FRs via indoor dust.

\section{Acknowledgements}

The authors acknowledges the National Council for Scientific and Technological Development (CNPq - Brazil) (grant number 401756/2013-0), the Program Science Without Borders (Brazil), the Foundation for Support of Science, Technology and Education (Brazil) and the Ministry of Education and Innovation of Spain.

\section{Appendix A. Supplementary data}

Supplementary data related to this article can be found at https://doi.org/10.1016/j.envpol.2017.10.110.

\section{References}

Abdallah, M.A.E., Covaci, A., 2014. Organophosphate flame retardants in indoor dust from Egypt: implications for human exposure. Environ. Sci. Technol. 48, 4782-4789.

Ait Bamai, Y., Shibata, E., Saito, I., Araki, A., Kanazawa, A., Morimoto, K. Nakayama, K., Tanaka, M., Takigawa, T., Yoshimura, T., Chikara, H., Saijo, Y., Kishi, R., 2014. Exposure to house dust phthalates in relation to asthma and allergies in both children and adults. Sci. Total Environ. 485-486, 153-163.

Ali, N., Dirtu, A.C., Eede, N.V.D., Goosey, E., Harrad, S., Neels, H., t Mannetje, A. Coakley, J., Douwes, J., Covaci, A., 2012. Occurrence of alternative flame retardants in indoor dust from New Zealand: indoor sources and human exposure assessment. Chemosphere 88, 1276-1282.

Ali, N., Ali, L., Mehdi, T., Dirtu, A.C., Al-Shammari, F., Neels, H., Covaci, A., 2013. Levels and profiles of organochlorines and flame retardants in car and house dust from Kuwait and Pakistan: implication for human exposure via dust ingestion. Environ. Int. 55, 62-70.

Ali, N., Eqani, S.A.M.A.S., Ismail, I.M.I., Malarvannan, G., Kadi, M.W., Albar, H.M.S., Rehan, M., Covaci, A., 2016a. Brominated and organophosphate flame retardants in indoor dust of Jeddah, Kingdom of Saudi Arabia: implications for human exposure. Sci. Total Environ. 569, 269-277.

Ali, N., Eqani, S.A.M.A.S., Ismail, I.M.I., Malarvannan, G., Kadi, M.W., Albar, H.M.S. Rehan, M., Covaci, A., 2016b. Brominated and organophosphate flame retardants in indoor dust of Jeddah, Kingdom of Saudi Arabia: implications for human exposure. Sci. Total Environ. 569-570, 269-277.

Allen, J.G., McClean, M.D., Stapleton, H.M., Webster, T.F., 2008. Critical factors in assessing exposure to PBDEs via house dust. Environ. Int. 34, 1085-1091. 
Besis, A., Samara, C., 2012. Polybrominated diphenyl ethers (PBDEs) in the indoor and outdoor environments - a review on occurrence and human exposure. Environ. Pollut. 169, 217-229.

Brandsma, S.H., De Boer, J., Leonards, P.E.G., Cofino, W.P., Covaci, A., 2013. Organophosphorus flame-retardant and plasticizer analysis, including recommendations from the first worldwide interlaboratory study. TrAC - Trends Anal. Chem. 43, 217-228.

Brommer, S., Harrad, S., 2015. Sources and human exposure implications of concentrations of organophosphate flame retardants in dust from UK cars, classrooms, living rooms, and offices. Environ. Int. 83, 202-207.

Cao, Z., Xu, F., Covaci, A., Wu, M., Wang, H., Yu, G., Wang, B., Deng, S., Huang, J., Wang, X., 2014. Distribution patterns of brominated, chlorinated, and phosphorus flame retardants with particle size in indoor and outdoor dust and implications for human exposure. Environ. Sci. Technol. 48, 8839-8846.

Cequier, E., Ionas, A.C., Covaci, A., Marcé, R.M., Becher, G., Thomsen, C., 2014 Occurrence of a broad range of legacy and emerging flame retardants in indoor environments in Norway. Environ. Sci. Technol. 48, 6827-6835.

Chan, L.Y., Kwok, W.S., 2000. Vertical dispersion of suspended particulates in urban area of Hong Kong. Atmos. Environ. 34, 4403-4412.

Chao, H.R., Tsou, T.C., Huang, H.L., Chang-Chien, G.P., 2011. Levels of breast milk PBDEs from southern taiwan and their potential impact on neurodevelopment. Pediatr. Res. 70, 596-600.

Cristale, J., Quintana, J., Chaler, R., Ventura, F. Lacorte, S., 2012. Gas chromatography/ mass spectrometry comprehensive analysis of organophosphorus, brominated flame retardants, by-products and formulation intermediates in water. J. Chromatogr. A 1241, 1-12.

Cristale, J., Lacorte, S., 2013. Development and validation of a multiresidue method for the analysis of polybrominated diphenyl ethers, new brominated and organophosphorus flame retardants in sediment, sludge and dust. J. Chromatogr. A 1305, 267-275.

Cristale, J., Hurtado, A., Gómez-Canela, C., Lacorte, S., 2016. Occurrence and sources of brominated and organophosphorus flame retardants in dust from different indoor environments in Barcelona, Spain. Environ. Res. 149, 66-76.

Dodson, R.E., Perovich, L.J., Covaci, A., Van Den Eede, N., Ionas, A.C., Dirtu, A.C., Brody, J.G., Rudel, R.A., 2012. After the PBDE phase-out: a broad suite of flame retardants in repeat house dust samples from California. Environ. Sci. Technol. 46, 13056-13066.

EURAR - European Union Risk Assessment Report, 2008a. Tris(2-chloro-1 methylethyl) phosphate (TCPP) risk assessment. http://www.echa.europa.eu/ documents/10162/13630/trd_rar_ireland_tccp_en.pdf, 23/05/2013.

EURAR - European Union Risk Assessment Report, 2008b. Tris[2-chloro-1-(chloromethyl)ethyl] phosphate (TDCP) Risk Assessment. http://www.echa.europa. eu/documents/10162/13630/trd_rar_ireland_tdcp_en.pdf, 23/05/2013.

EURAR - European Union Risk Assessment Report, 2009. Tris (2-chloroethyl) phosphate, TCEP. In: http://www.baua.de/en/Chemicals-Act-biocide-procedure/ Documents/RAR-068.pdf?_blob=publicationFile \&V=1.

Hassan, Y., Shoeib, T., 2015. Levels of polybrominated diphenyl ethers and nove flame retardants in microenvironment dust from Egypt: an assessment of human exposure. Sci. Total Environ. 505, 47-55.

Hee, S.S.Q., Peace, B., Clark, C.S., Boyle, J.R., Bornschein, R.L., Hammond, P.B., 1985 Evolution of efficient methods to sample lead sources, such as house dust and hand dust, in the homes of children. Environ. Res. 38, 77-95.

Jones-Otazo, H.A., Clarke, J.P., Diamond, M.L., Archbold, J.A., Ferguson, G., Harner, T., Richardson, G.M., Ryan, J.J., Wilford, B., 2005. Is house dust the missing exposure pathway for PBDEs? An analysis of the urban fate and human exposure to PBDEs. Environ. Sci. Technol. 39, 5121-5130.
Kademoglou, K., Xu, F., Padilla-Sanchez, J.A., Haug, L.S., Covaci, A., Collins, C.D., 2017. Legacy and alternative flame retardants in Norwegian and UK indoor environment: implications of human exposure via dust ingestion. Environ. Int. 102, $48-56$.

Khan, M.U., Li, J., Zhang, G., Malik, R.N., 2016. New insight into the levels, distribution and health risk diagnosis of indoor and outdoor dust-bound FRs in colder, rural and industrial zones of Pakistan. Environ. Pollut. 216, 662-674.

Kim, J.W., Isobe, T., Sudaryanto, A., Malarvannan, G., Chang, K.H., Muto, M., Prudente, M., Tanabe, S., 2013. Organophosphorus flame retardants in house dust from the Philippines: occurrence and assessment of human exposure. Environ. Sci. Pollut. Res. 20, 812-822.

Kojima, H., Takeuchi, S., Itoh, T., Iida, M., Kobayashi, S., Yoshida, T., 2013. In vitro endocrine disruption potential of organophosphate flame retardants via human nuclear receptors. Toxicology 314, 76-83.

Lyche, J.L., Rosseland, C., Berge, G., Polder, A., 2015. Human health risk associated with brominated flame-retardants (BFRs). Environ. Int. 74, 170-180.

Mizouchi, S., Ichiba, M., Takigami, H., Kajiwara, N., Takamuku, T., Miyajima, T., Kodama, H., Someya, T., Ueno, D., 2015. Exposure assessment of organophosphorus and organobromine flame retardants via indoor dust from elementary schools and domestic houses. Chemosphere 123, 17-25.

OJEU - Official Journal of the European Union, 2003. Directive 2003/11/ec of the European Parliament and of the Council of 6 February 2003. L 42/45.

Qi, H., Li, W.-L., Zhu, N.-Z., Ma, W.-L., Liu, L.-Y., Zhang, F., Li, Y.-F., 2014. Concentrations and sources of polycyclic aromatic hydrocarbons in indoor dust in China. Sci. Total Environ. 491-492, 100-107.

Rauert, C., Harrad, S., 2015. Mass transfer of PBDEs from plastic TV casing to indoor dust via three migration pathways - a test chamber investigation. Sci. Total Environ. 536, 568-574.

Saito, I., Onuki, A., Seto, H., 2007. Indoor organophosphate and polybrominated flame retardants in Tokyo. Indoor Air 17, 28-36.

SCHER - Scientific Committee on Health and Environmental Risks, 2012. Opinion on tris(2-chloroethyl)phosphate (TCEP) in Toys. http://ec.europa.eu/health/ scientific_committees/environmental_risks/docs/scher_o_158.pdf, 23/05/2013.

Schreder, E.D., La Guardia, M.J., 2014. Flame retardant transfers from U.S. households (dust and laundry wastewater) to the aquatic environment. Environ. Sci. Technol. 48, 11575-11583.

SpecialChem, 2013. Flame retardants Center. http://www.specialchem4polymers. com/tc/flame-retardants/index.aspx, 06/05/2013.

Tajima, S., Araki, A., Kawai, T., Tsuboi, T., Ait Bamai, Y., Yoshioka, E., Kanazawa, A., Cong, S., Kishi, R., 2014. Detection and intake assessment of organophosphate flame retardants in house dust in Japanese dwellings. Sci. Total Environ. 478, 190-199.

UNEP - United Nations Environment Programme, 2009. Guidance on feasible flameretardant alternatives to commercial pentabromodiphenyl ether, http://chm. pops.int/Implementation/NationalImplementationPlans/Guidance/ GuidancefortheinventoryofPBDEs/tabid/3171/Default.aspx, 03/11/2017.

USEPA - U.S. Environmental Protection Agency, 2009. Polybrominated diphenyl ethers (PBDEs) Action plan. https://www.epa.gov/sites/production/files/201509/documents/pbdes_ap_2009_1230_final.pdf, 03/08/2016.

WHO - World Health Organization, 1998. Flame retardants: tris(chloropropyl) phosphate and tris(2-chloroethyl) phosphate. In: Environmental Health Criteria, vol. 209, p. 1998. Geneva, Switzerland.

Yamamoto, N., Takahashi, Y., Yoshinaga, J., Tanaka, A., Shibata, Y., 2006. Size distributions of soil particles adhered to children's hands. Archives Environ. Contam. Toxicol. 51, 157-163. 